\title{
ANALISANDO A ESCRAVIDÃO NO SÉCULO XIX: SOB A ÓTICA DO JORNAL O CACHOEIRANO E AUTORES CONTEMPORÂNEOS
}

\author{
Bruna Gaspar da Silva ${ }^{1}$ \\ Izabella Obolari Peixoto Seraphini ${ }^{2}$ \\ Larissa Cazadine Bebber ${ }^{3}$ \\ Jocimara de Oliveira Silva ${ }^{4}$ \\ Rayanne Braga Osto ${ }^{5}$ \\ Prisciliana Costa Ventura ${ }^{6}$ \\ Victor Silva Salaroli do Nascimento ${ }^{7}$ \\ Mateus Augusto Almeida Martins ${ }^{8}$ \\ Mellina de Fátima Neres de Sousa Curty ${ }^{9}$
}

Resumo: Historicamente sabemos que a escravidão possibilitou o desenvolvimento econômico brasileiro. Também sabemos que, esse desenvolvimento foi promovido à custa do trabalho árduo, pesado, e muitas vezes sofrido e injusto aos escravos. O negro, a partir de suas reivindicações, buscou ocupar seu espaço na sociedade, onde exerceu papel fundamental na formação da sociedade nacional, resgatando e valorizando suas contribuições sociais, econômicas e políticas. O presente trabalho busca mostrar de forma breve o contexto em que os escravos viviam, especialmente na Província do Espírito Santo e como aos poucos a escravidão foi sendo criticada pelo jornal O Cachoeirano.

Palavras-chave: Escravidão; Espírito Santo; Jornal 'O Cachoeirano'.

\footnotetext{
${ }^{1}$ Ensino Fundamental, Brasil. E-mail: brunagsilva@hotmail.com.

2 Ensino Fundamental, Brasil. E-mail: izabella59_@hotmail.com.

3 Ensino Fundamental, Brasil. E-mail: cazadinebebber@gmail.com.

${ }^{4}$ Ensino Fundamental, Brasil. E-mail: joci_04_@gmail.com.

5 Ensino Fundamental, Brasil. E-mail: rayanne.ostro@hotmail.com.

${ }^{6}$ Especialista em Filosofia Moderna e Contemporânea. E-mail: lilaventura@hotmail.com.

7 Graduando em História, Brasil, E-mail: victorsalaroli26@gmail.com.

${ }^{8}$ Graduado em História, Brasil. E-mail: m_ateusaugusto@hotmail.com.

9 Mestre em História, Brasil. E-mail: mell.curty@gmail.com.
} 